\title{
ANALISIS PELAYANAN KEFARMASIAN DI PUSKESMAS TOSIBA KABUPATEN KOLAKA
}

\author{
Musdalipah*, Muh.Syaiful Saehu, Asmiati \\ Akademi Farmasi Bina Husada Kendari \\ E-mail : musdalipahapt@gmail.com
}

\begin{abstract}
INTISARI
Pelayanan Kefarmasian merupakan kegiatan yang bertujuan untuk mengidentifikasi, mencegah, dan menyelesaikan masalah terkait Obat. Tuntutan pasien dan masyarakat akan peningkatan mutu Pelayanan Kefarmasian, mengharuskan adanya perluasan dari paradigma lama yang berorientasi kepada produk (drug oriented) menjadi paradigma baru yang berorientasi pada pasien (patient oriented) dengan filosofi Pelayanan Kefarmasian (pharmaceutical care). Tujuan penelitian untuk mengetahui pelayanan kefarmasian di puskesmas Tosiba Kabupaten Kolaka. Jenis penelitian dilakukan dengan metode deskriptifdengan pengambilan data secara retrospektif. Sampel penelitian terdiri dari kepala puskesmas Tosiba, Apoteker dan Asisten Apoteker. Data dianalisis secara deskriptif dan dijabarkan dalam bentuk narasi. Hasil penelitian menunjukkan pengelolaan obat dan pengkajian resep pada puskesmas Tosiba kabupaten Kolaka sudah sesuai dengan standar pelayanan kefarmasian, tetapi dalam hal sarana dan prasarana belum memadai berdasarkan standar pelayanan kefarmasian.
\end{abstract}

Kata Kunci : Pelayanan Kefarmasian, Pengelolaan Obat, Pengkajian Resep

\begin{abstract}
Pharmaceutical care is an activity that aims to identify, prevent and solve drug related problems. The demands of patients and the public on the improvement of the quality of pharmaceutical care, require that the extension of the old paradigma wich oriented to the product (drug oriented) into a patient oriented (patient oriented) with the philosophy of pharmaceutical care. The purpose of this study is to find out the pharmaceutical care in puskesmas tosiba kolaka district. This type of research is done by descriptive method. Research method used is descriptive with retrospektive data retriveal. The sample in this study consisted of the head of tosiba puskesmas, pharmacist and assistent pharmacist. Data are analyzed descriptively and elaborated in narrative form. The results showed that the management of drugs and prescription assessment at puskesmas tosiba kolaka accordance with the standard of pharmaceutical care but facilities and
\end{abstract}


infrastructure that has not been sufficient and also exposed to several other factors.

Keywords: Pharmaceutical Care, Management Of Drugs, Assesment of Prescription

PENDAHULUAN

Pelayanan kefarmasian adalah

suatu pelayanan langsung dan bertanggung jawab kepada pasien yang berkaitan dengan sediaan farmasi dengan maksud mencapai hasil yang pasti untuk meningkatkan mutu kehidupan pasien. Pelayanan kefarmasian di Puskesmas merupakan satu kesatuan yang tidak terpisahkan dari pelaksanaan upaya kesehatan, yang berperan penting dalam meningkatkan mutu pelayanan kesehatan bagi masyarakat.

Pengelolaan obat merupakan salah satu kegiatan pelayanan kefarmasian, yang dimulai dari perencanaan, permintaan, penerimaan, penyimpanan, pendistribusian, pengendalian, pencatatan dan pelaporan serta pemantauan dan evaluasi. Tujuannya adalah untuk menjamin kelangsungan ketersediaan dan keterjangkauan obat yang efisien, efektif dan rasional, meningkatkan kompetensi/kemampuan tenaga kefarmasian, mewujudkan sistem informasi manajemen, dan melaksanakan pengendalian mutu pelayanan (Permenkes, 2014).

Berdasarkan observasi awal Puskesmas Tosiba memiliki 6 tenaga kefarmasian yang terdiri dari 1 Apoteker, 4 S1 Farmasi dan 1 D3 Farmasi. Hasil pengambilan data awal Puskesmas Tosiba Kabupaten Kolaka menunjukkan bahwa belum adanya dokumentasi mengenai pengelolaan obat. Olehnya itu, penelitian ini untuk menganalisis pelaksanaan pelayanan kefarmasian berdasarkan Permenkes No 30 tahun 2014 tentang pelayanan kefarmasian.

\section{METODE PENELITIAN}

Metode penelitian yang digunakan adalah deskriptif dengan pengambilan data secara retrospektif. Sampel penelitian terdiri dari Kepala Puskesmas Tosiba, Apoteker dan Asisten Apoteker. Data dianalisis secara deskriptif dan dijabarkan dalam bentuk narasi. 


\section{HASIL DAN PEMBAHASAN}

Berdasarkan hasil penelitian diperoleh data sebagai berikut :

\section{Perencanaan Obat di Puskesmas Tosiba Kabupaten Kolaka}

Tabel.1 Perencanaan Obat di Puskesmas Tosiba Kabupaten Kolaka

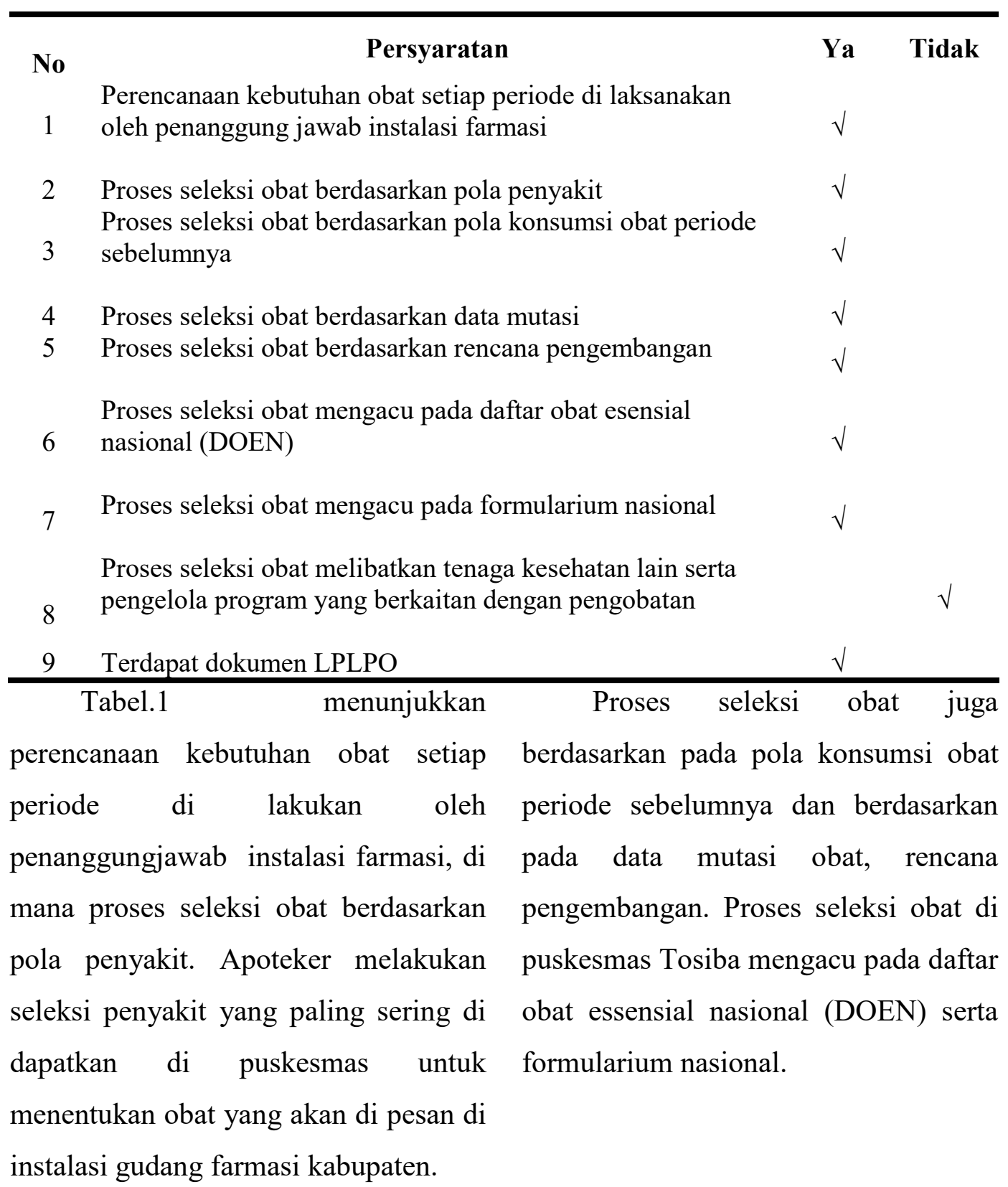




\section{Permintaan Obat di Puskesmas Tosiba Kabupaten Kolaka}

Tabel. 2 Permintaan Obat di Puskesmas Tosiba Kabupaten Kolaka

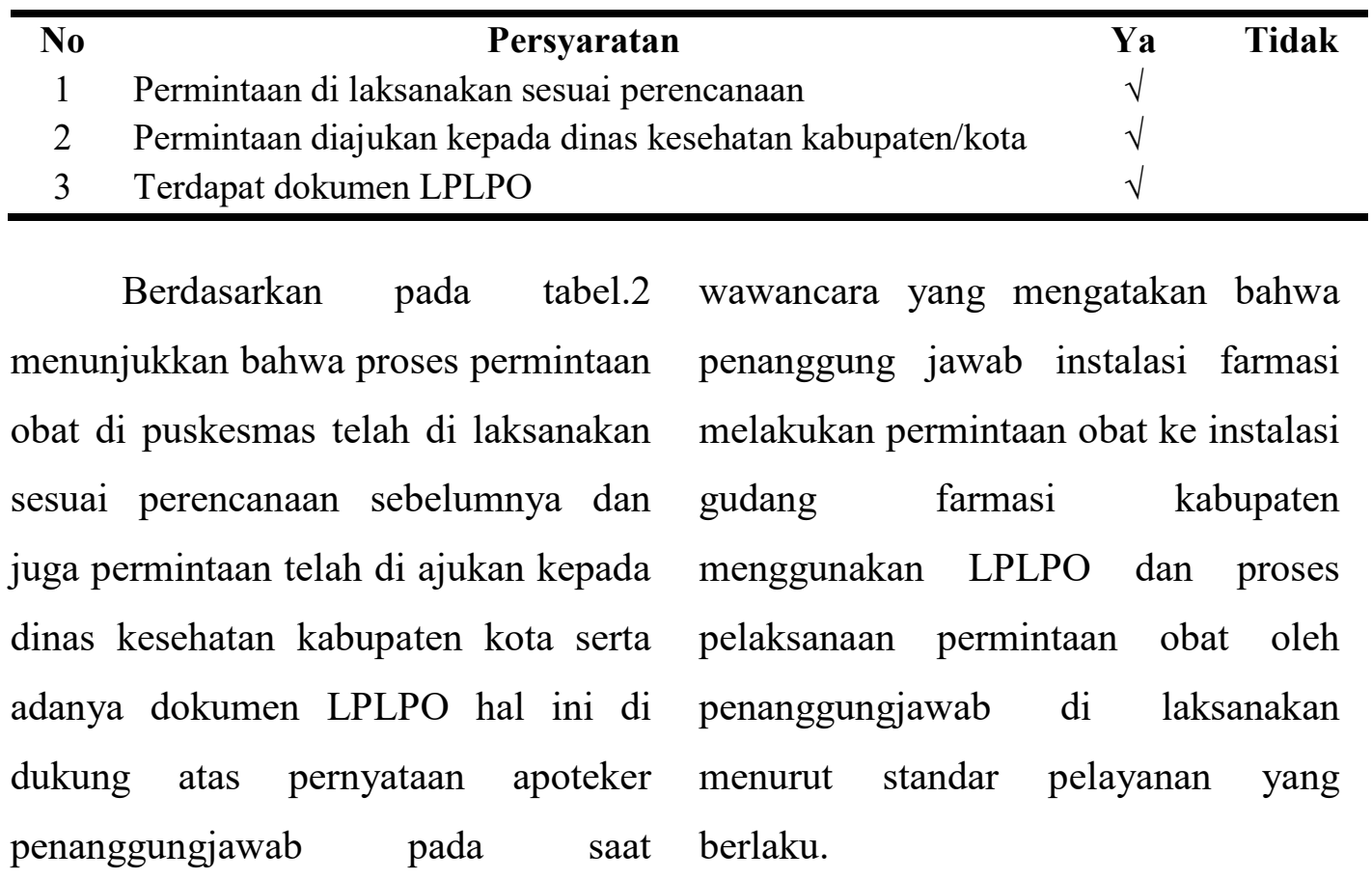

\section{Penerimaan Obat di Puskesmas Tosiba Kabupaten Kolaka}

Tabel.3 Penerimaan Obat di Puskesmas Tosiba Kabupaten Kolaka

\begin{tabular}{clcc}
\hline No. & \multicolumn{1}{c}{ Persayaratan } & Ya & Tidak \\
1 & Melakukan pengecekan kemasan/ peti sesuai LPLPO & $\sqrt{ }$ & \\
2 & Melakukan pengecekan jenis dan jumlah obat sesuai LPLPO & $\sqrt{ }$ & \\
3 & Melakukan pengecekan bentuk obat sesuai LPLPO & $\sqrt{ }$ \\
\hline
\end{tabular}

Berdasarkan pada tabel.3 dukung atas pernyataan apoteker pada menunjukkan pada saat penerimaan saat wawancara bahwa setelah obat apoteker yang di dampingi oleh melakukan permintaan obat maka assisten apoteker melakukan penanggung jawab akan melakukan pengecekan kemasan atau peti sesuai penerimaan obat di mana pada proses LPLPO dan melakukan pengecekan penerimaan penanggung jawab di jenis dan jumlah obat serta bentuk obat dampingi oleh assisten untuk sesuai dengan LPLPO, hal ini pun di melakukan pengecekan. 


\section{Penyimpanan Obat di Puskesmas Tosiba Kabupaten Kolaka}

Tabel.4 Penyimpanan Obat di Puskesmas Tosiba Kabupaten Kolaka

\begin{tabular}{clcc}
\hline No & \multicolumn{1}{c}{ Persyaratan } & Ya & Tidak \\
1 & Penyimpanan berdasarkan bentuk dan jenis sediaan & $\sqrt{ }$ & \\
2 & Penyimpanan berdasarkan farmakologi terapi & $\sqrt{ }$ & \\
3 & Penyimpanan berdasarkan alfabetis & $\sqrt{ }$ & \\
4 & Penyimpanan berdasarkan system FIFO dan FEFO & $\sqrt{ }$ \\
5 & $\begin{array}{l}\text { Penyimpanan berdasarkan pertimbangan stabilitas (suhu, } \\
\text { cahaya, kelembaban) }\end{array}$ & $\sqrt{ }$ \\
6 & $\begin{array}{l}\text { Penyimpanan berdasarkan pertimbangan mudah atau } \\
\text { tidaknya meledak/terbakar }\end{array}$ & $\sqrt{ }$ \\
7 & Narkotika dan psikotropika disimpan di lemari khusus & $\sqrt{ }$ \\
\hline
\end{tabular}

Berdasarkan tabel.4 stabilitas (suhu, cahaya, dan menunjukkan pada proses kelembaban) serta mudah atau tidakya penyimpanan obat di puskesmas tosiba meledak atau terbakar sedangkan untuk berdasarkan bentuk dan jenis sediaan, obat jenis narkotika dan psikotropika di alfabetis dan telah menggunakan simpan dalam lemari khusus. sistem FIFO dan FEFO selain itu penyimpanan juga mempertimbangkan

\section{Pendistribusian Obat di Puskesmas Tosiba Kabupaten Kolaka}

Tabel.5 Pendistribusian Obat di Puskesmas Tosiba Kabupaten Kolaka

\begin{tabular}{clcc}
\hline No & \multicolumn{1}{c}{ Persyaratan } & Ya & Tidak \\
1 & Pemberian obat sesuai resep yang diterima (floor stock) & $\sqrt{ }$ & \\
2 & $\begin{array}{l}\text { Pemberian obat untuk per sekali minum (dispensing dosis } \\
\text { unit) atau kombinasi }\end{array}$ & $\sqrt{ }$ \\
3 & Penyerahan obat sesuai dengan kebutuhan (floor stock) & $\sqrt{ }$ \\
\hline
\end{tabular}

Berdasarkan tabel.5 kesimpulan bahwa obat yang berada di menunjukkan bahwa proses puskesmas didistribusikan ke Pustu, pendistribusian obat di lakukan sesuai Poskesdes. Penyaluran obat juga resep yang di terima, untuk per sekali dilakukan dibagian sub -sub puskesmas minum atau kombinasi dan juga seperti,(UGD), ruang rawat inap, ruang penyerahan obat sesuai dengan poli umum dan poli gigi.

kebutuhan. Berdasarkan hasil wawancara dengan informan, diperoleh 


\section{Pengendalian Obat di Puskesmas Tosiba Kabupaten Kolaka}

Tabel.6 Pengendalian Obat di Puskesmas Tosiba Kabupaten Kolaka

\begin{tabular}{clcc}
\hline No & \multicolumn{1}{c}{ Persyaratan } & Ya & Tidak \\
1 & Melakukan pengendalian persediaan & $\sqrt{ }$ & \\
2 & Melakukan pengendalian penggunaan & $\sqrt{ }$ & \\
3 & Melakukan penanganan obat hilang, rusak dan kadaluwarsa & $\sqrt{ }$ & \\
\hline
\end{tabular}

Berdasarkan

tabel.6 dari pernyataan kepala puskesmas

menunjukkan bahwa pada proses tosiba yang menyatakan bahwa akan pengendalian obat di puskesmas membeli obat di apotek luar tosiba yaitu mereka melakukan menggunakan dana BPJS atas izin pengendalian persediaan, penggunaan dari kepala puskesmas apabila terjadi serta penanganan obat hilang, rusak kekosongan obat.

dan kadaluwarsa hal ini di dukung

\section{Pencatatan, Pelaporan dan Pengarsipan Obat di Puskesmas Tosiba Kabupaten Kolaka}

Tabel.7 Pencatatan, Pelaporan dan Pengarsipan Obat di Puskesmas Tosiba Kabupaten Kolaka

\begin{tabular}{clcc}
\hline No & & Ya & Tidak \\
1 & Tersedia kartu stok & $\sqrt{ }$ & \\
2 & Tiap lembar kartu stok hanya untuk mencatat data mutasi & $\sqrt{ }$ & \\
3 & 1 jenis obat & $\sqrt{ }$ & \\
4 & Ada catatan harian pemakaian obat & $\sqrt{ }$ & \\
& Kada berita acara pengembalian obat bila obat rusak atau & & \\
5 & Setiap terjadi mutasi obat langsung dicatat dalam kartu & $\sqrt{ }$ \\
6 & stok & $\sqrt{ }$ \\
7 & Pencatatan pemakaian obat harian & $\sqrt{ }$ \\
8 & Membuat laporan penggunaan obat setiap bulan & $\sqrt{ }$ \\
\hline
\end{tabular}

Berdasarkan tabel.7 menunjukkan lembar kartu stock di gunakan hanya bahwa pencatatan, pelaporan dan untuk mencatat data mutasi satu jenis pengarsipan obat di puskesmas tersebut obat setiap terjadi mutasi obat langsung meliputi kartu stock di mana untuk satu dicatat dalam kartu stock, terdapat pula 
catatan harian pemakaian obat dan jika untuk penerimaan dan pengeluaran ada obat rusak atau kadaluwarsa maka yang dijumlah tiap akhir bulan serta akan di buatkan berita acara membuat laporan penggunaan obat tiap pengembalian. Pencatatan dilakukan bulan.

\section{Pemantauan dan Evaluasi Obat di Puskesmas Tosiba Kabupaten Kolaka}

Tabel.8 Pemantauan dan Evaluasi Obat di Puskesmas Tosiba Kabupaten Kolaka

\begin{tabular}{clcc}
\hline No & \multicolumn{1}{c}{ Persyaratan } & Ya & Tidak \\
1 & Memiliki tim pemantau dan evaluasi pengelolaan obat & $\sqrt{ }$ & \\
2 & Apa pemantauan dan evaluasi dilakukan secara periodik & $\sqrt{ }$ & \\
\hline
\end{tabular}

Berdasarkan tabel 8 menunjukkan tim serta pemantauan di lakukan pada proses pemantauan dan secara periodik.

evaluasi puskesmas tosiba memiliki

\section{Pengkajian Resep, Penyerahan dan Pemberian Informasi Obat di Puskesmas Tosiba Kabupaten Kolaka}

Tabel.9 Pengkajian Resep, Penyerahan dan Pemberian Informasi Obat di Puskesmas Tosiba Kab Upaten Kolaka

\begin{tabular}{clcc}
\hline No & \multicolumn{1}{c}{ Persyaratan } & Ya & Tidak \\
1 & Ada nama, umur, jenis kelamin dan berat badan pasien & $\sqrt{ }$ & \\
2 & Ada nama dan paraf dokter & $\sqrt{ }$ & \\
3 & Ada tanggal resep & $\sqrt{ }$ & \\
4 & Ada ruangan/unit asal resep & $\sqrt{ }$ & \\
5 & Ada bentuk dan kekuatan sediaan & $\sqrt{ }$ \\
6 & Ada dosis dan jumlah obat & $\sqrt{ }$ \\
7 & Ada stabilitas dan ketersediaan & $\sqrt{ }$ \\
8 & Ada aturan dan cara penggunaan & $\sqrt{ }$ \\
9 & Ada inkompatibilitas (ketidakcampuran obat) & $\sqrt{ }$ \\
10 & Tepat dosis, indikasi dan waktu penggunaan obat & $\sqrt{ }$ \\
11 & Ada duplikasi pengobatan & $\sqrt{ }$ \\
12 & Ada alergi, interaksi dan efek samping obat & $\sqrt{ }$ \\
13 & Ada kontra indikasi & $\sqrt{ }$ \\
14 & Ada efek adiktif & $\sqrt{ }$ \\
15 & Menyiapkan dan meracik obat & $\sqrt{ }$ \\
16 & Memberikan label/etiket & $\sqrt{ }$ \\
& Menyerahkan sediaan farmasi dengan informasi yang & & $\sqrt{ }$ \\
17 & memadai & Melakukan pendokumentasian pada saat penyerahan & \\
\hline
\end{tabular}


Berdasarkan tabel.9 menunjukkan bahwa pada resep telah terdapat nama, umur, berat bada pasien namun belum terdapat nama dokter, paraf dokter dan jenis kelamin pasien. Persyaratan lain seperti tanggal resep, ruangan asal resep, dosis dan jumlah stabilitas dan

\section{DAFTAR PUSTAKA}

Aedi Nur. 2010. Pengolahan dan Data Hasil Penelitian. Bandung: universitas pedidikan Indonesia

Anjarwati rori. 2009. Evaluasi Kesesuaian Pengelolaan Obat Pada Puskesmas dengan Standar Pengelolaan Obat Yang Ada di Kabupaten Sukoharjo Tahun 2009. Surakarta: Universitas muhammadiyah surakarta

Bilqis siti ulfah. 2015. Kajian Administrasi, Farmasetik dan Klinis Resep Pasien Rawat Jalan di Rumkital Dr. Mintohardjo Pada Bulan Januari 2015. Jakarta: UIN syarif hidayatullah

Chaira syukriati. 2016. Evaluasi Pengelolaan Obat pada Puskesmas di Kota Pariaman. Sumatera barat: Universitas andalas padang

Costa Almira, R.S.D. 2015. Evaluasi Mutu Pelayanan Apotek Rawat Jalan Berdasarkan Standar Pelayanan Kefarmasian di Rumah Sakit Rawalumbu Bekasi. Jakarta: Universitas Esa Unggul. ketersediaan serta aturan dan cara penggunaan obat telah terdapat pada resep. Hasil wawancara menyebutkan masih di temukan inkompatibilitas obat dan duplikasi obat. Selain itu, penggunaan obat lain digunakan untuk menghilangkan efek samping obat.

Darmawansyah, dkk. 2012. Analisis Pengelolaan Obat di Puskesmas Kampala Kecamatan Sinjai Timur Kabupaten Sinjai Tahun 2011. Makassar: FKM UNHAS

Delfia megasari. 2016. Evaluasi Pengadaan Obat di Puskesmas Sleman Yogyakarta. Yogyakarta: 'Universitas sanata dharma

Djuna sarlin. 2014. Studi Manajemen Pengelolaan Obat Di Puskesmas Labakkang Kabupaten Pangkep. Makassar: FKM UNHAS

Dominica dwi, dkk. 2016. Pengaruh Kehadiran Apoteker Terhadap Pelayanan Kefarmasian di Apotek di Kota Padang. Sumatera Barat: Universitas Andalas

Eka Arimbawa Putu.2014. Hubungan Pelayanan Kefarmasian Dengan Kepuasan Pasien Menggunakan Jasa Apotek Di Kota Denpasar. Denpasar : Universitas Udayana.

Hartono joko puji. 2007. Analisis Proses Perencanaan Kebutuhan Obat Publik Untuk Pelayanan Kesehatan Dasar (Pkd) di Puskesmas Se Wilayah Kerja Dinas Kesehatan Kota Tasikmalaya. Semarang: Universitas Diponogoro. 
Hiborang sera s. 2016. Gambaran Pelaksanaan Pengelolaan Obat di Puskesmas Paniki Bawah Kota Manado Tahun 2016. Manado: Universitas Sam Ratulangi

Husnawati. 2016. Sistem Pengelolaan Obat Di Puskemas di Kecamatan Rambah Samo Kabupaten Rokan Hulu - Riau. Riau: sekolah tinggi ilmu farmasi riau

Istiqomah Fatimah Nur. 2012. Evaluasi Implementasi Standar Pelayanan Kefarmasian Oleh Apoteker. Yogyakarta: Universitas Gadjah Mada

Kawahe Monika, dkk. 2015. Hubungan antara Mutu Pelayanan

Kefarmasian dengan Kepuasan

Pasien Rawat Jalan di Puskesmas

Teling Atas Kota Manado.

Manado: Universitas Sam

Ratulangi

Kementrian Kesehatan 2004, Keputusan Menteri Kesehatan Republik Indonesia Nomor 128/Menkes/Sk/IX/2004, Tentang Kebijakan Dasar Pusat Kesehatan Masyarakat, Jakarta, Kementrian Kesehatan Republik Indonesia

Kementrian Kesehatan 2004, Keputusan Menteri Kesehatan Republik Indonesia Nomor 1027/Menkes/Sk/II/2004, Tentang Standar Pelayanan Kefarmasian di Apotek, Jakarta, Kementrian Kesehatan Republik Indonesia

Kementrian Kesehatan 2014, Peraturan Menteri Kesehatan Repubik Indonesia Nomor 30 Tahun 2014, Tentang Standar Pelayanan Kefarmasian di
Puskesmas, Jakarta, Kementrian Kesehatan Republik Indonesia

Kementrian Kesehatan 2014, Peraturan Menteri Kesehatan Repubik Indonesia Nomor 58 Tahun 2014, Tentang Standar Pelayanan Kefarmasian di Rumah sakit, Jakarta, Kementrian Kesehatan Republik Indonesia

Kementrian Kesehatan 2014, Peraturan Menteri Kesehatan Republik Indonesia Nomor 75 Tahun 2014, Tentang Pusat Kesehatan Masyarakat, Jakarta, Kementrian Kesehatan Republik Indonesia

Kementrian Kesehatan 2016, Peraturan Menteri Kesehatan Repubik Indonesia Nomor 44 Tahun 2016, Tentang Pedoman Manajemen Puskesmas, Jakarta, Kementrian Kesehatan Republik Indonesia 